\title{
Impaction of an Upper Gastrointestinal Endoscope in the Distal Esophagus: Alternative Method of Removal by Double Endoscopy without Fluoroscopic Assistance
}

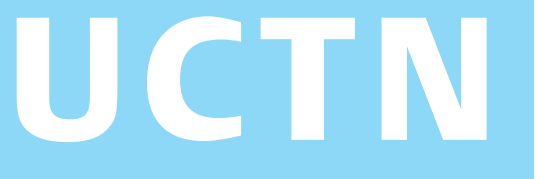

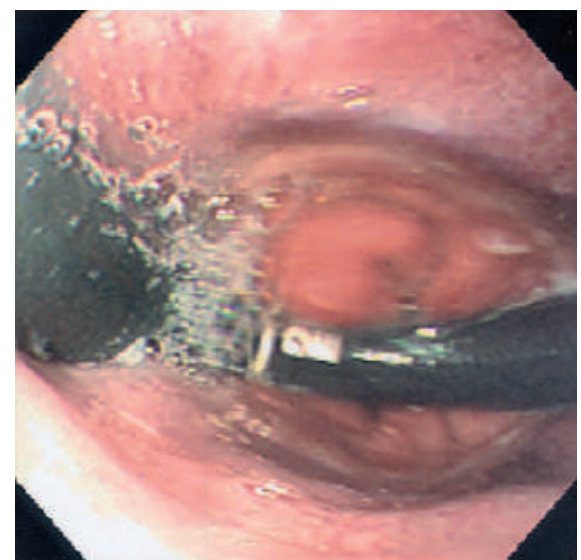

Figure 1 Endoscopic visualization of a portion of the first impacted endoscope above the gastroesophageal junction.

A 24-year-old man had suffered from epigastralgia and acid regurgitation for many years. After local anesthesia, upper gastrointestinal endoscopy was performed without difficulty. Some hematin-coated spots were noted at the gastric body, and loosening of the gastroesophageal junction. During the retroflexion procedure, the endoscope became impacted in the distal esophagus when the patient gave a large belch. Although the lumen was clearly visible, attempts at external traction were unsuccessful because resistance was encountered. In addition, it was not possible to release the impacted loop by advancing the scope.

After several failed attempts, a second flexible endoscope was inserted without fluoroscopic assistance. The first endoscope was found to be within the distal esophagus as expected (Figure $\mathbf{1}$ ), as a Ushaped loop. It was then released using a double-endoscopy technique (Figure 2). The patient has been followed up, with no untoward events.

The currently used panendoscope has a shaft diameter of around $9 \mathrm{~mm}$. The esophagus, whose lumen can distend up to $20-30 \mathrm{~mm}$ laterally [1], is at least the size of two endoscope diameters. However, when there is impaction, the endo-

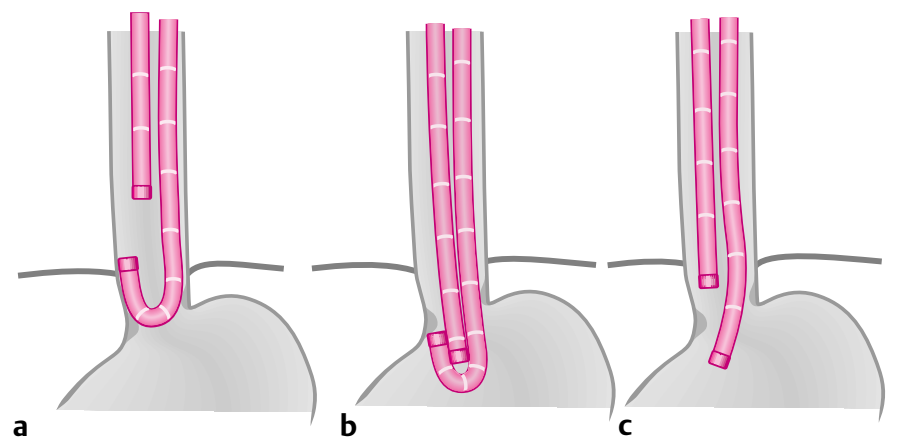

Figure 2 Doubleendoscopy removal technique. a A second endoscope is used to visualize the impaction. $\mathbf{b}$ The impacted scope is slowly pushed into the stomach using a second endoscope. c The two endoscopes are removed after advancement into the stomach.

scope remains stuck within the esophagus because simple retrograde traction on the endoscope results only in some flattening of the proximally created loop. The Olympus GIF XQ240 endoscope, has a minimal radius of curvature of about 38-40 mm, below which it cannot be further flattened. The curved portion pushes against the esophagus when traction is applied. However, further advancement of the endoscope also cannot solve the impaction because movement of the endoscope is still restricted to above the gastroesophageal junction.

Impaction of an endoscope at retroflexion in the distal esophagus, in a patient with hiatal hernia or total gastrectomy, has been previously described [2,3]. The greatest risk of impaction of an endoscope occurs during the retroflexion procedure in patients with a loose gastroesophageal junction.

This example makes it clear that the use of a second endoscope is crucial for identifying the impacted loop and resolving this potential hazard, if the first endoscope could not be extracted easily.

\section{Competing interests: None}

P.-M. Huang1, H.-P. Wang' ${ }^{2}$ C.-N. Chen', L.-H. Chen', Y.-C. Lee ${ }^{1}$

${ }^{1}$ Department of Surgery and Traumatology, National Taiwan University Hospital and National Taiwan University College of Medicine, Taipei, Taiwan

2 Department of Emergency Medicine, National Taiwan University Hospital and National Taiwan University College of Medicine, Taipei, Taiwan.

\section{References}

${ }^{1}$ Pope CE 2nd. Normal anatomy and developmental anomalies. In: Sleisenger MH, Fordtran JS (eds) Gastrointestinal disease. 5th ed. Philadelphia: WB Saunders 1993: 311 318

2 Schrock TR. Complications of gastrointestinal endoscopy. In: Sleisenger MH, Fordtran JS (eds)Gastrointestinal and liver disease: pathophysiology, diagnosis, management. 6th ed.Philadelphia: WB Saunders 1998: $301-309$

${ }^{3}$ Chen MH, Yang JC, Wang JT et al. Solution to the dilemma of retrieving an endoscope from the esophagus. Gastrointest Endosc 1999; 49: 259-261

\section{Corresponding Author}

\section{Y.-C. Lee, MD, PhD}

Department of Surgery and Traumatology National Taiwan University Hospital

7 Chung-Shan S. Rd.

Taipei 100, Taiwan

Fax: $\quad+886-2-2393-0877$

E-mail: wuj@ha.mc.ntu.edu.tw 